\title{
Echocardiography evaluation of left ventricular function post Percutaneous Coronary Intervention to totally occluded coronary arteries
}

\author{
Khaled A.Emam El Khashab ${ }^{(1)}$, Sameh E.Sadek ${ }^{(2)}$, Haitham S.Gharib \\ ${ }^{(3)}$ and Mina S.Abdo ${ }^{(4)}$. \\ (1) professor of Cardiology, Faculty of Medicine Fayoum University. \\ (2)professor of Cardiology, Military Medical Academy. \\ (3)lecturer of Cardiology, Faculty of Medicine Fayoum University. \\ (4) Department of Cardiology, Faculty of Medicine Fayoum University.
}

\section{Corresponding author: prof . Khaled A.Emam El Khashab}

\section{Tel:01005123662}

\section{ABSTRACT}

We aimed to Evaluation of left ventricular function by Echocardiography post Percutaneous Coronary Intervention to totally occluded coronary arteries.

Methods: In 100 consecutive patients with chronic totally occluded coronary vessel, LV systolic function were measured by transthoracic Echocardiograrphy before and after successful CTO PCI.

Results: The study was conducted on 100 patient collected from department of cardiology, Fayoum University all patients were diagnosed as chronic total occlusion of coronary arteries, L.V systolic function was compared between

\section{INTRODUCTION}

The coronary arteries provide blood to the cardiac muscle and no substitute blood supply exists, so an obstruction in the coronary arteries decreases the supply of blood to cardiac muscle.

Ischemic left ventricular (L.V.) dysfunction is pre- procedural echocardiographic study and that done within 6 months after the procedure. L.V. Function Improvement was observed in $76 \%$ of patients. With no change in $14 \%$ and worsening in $10 \%$ of studied patints.

Conclusion: PCI for a CTO has a beneficial effect on LV functions, myocardial contractility .

KEY WORDS: chronic total occlusion, ejection fraction, left ventricular function, Coronary artery disease and Percutaneous Coronary Intervention.

there in a number of clinical diseases in whom myocardial revascularization outcomes in an improvement of LV systolic function, patients functional class and their survival ratio. [1]

Left ventricle (L.V.), being the pressure producer for the blood supply to all the body's organs, is gifted with a chamber which has thick myocardial walls. LV 
chamber does not exactly equivalent to any measurable geometric form, and in a healthy heart, it may be similar to an elongated ellipse with a conical apex. In unhealthy states, the form may changes globally or regionally, and this nonconformity of form. [2]

Few statistics present concerning the consequence of revascularization on left ventricular L.V.

geometry in patients with LV systolic dysfunction and viable myocardium. We will put forward that patients with chronic ischemic LV dysfunction but viable myocardium will have better LV geometry after revascularization, which in turn will enhance long-term outcome. [3]

Non-invasive testing is necessary for diagnosis which can be matched to the pathophysiologic alterations that occur in hibernating myocardium. [2]

Echocardiography is an perfect initial screening test in these patients, because of its broad availability, low cost, and comparable levels of accuracy to other more costly modalities. 


\section{PATIENTS AND METHODS}

| Data sources and eligibility criteria

Our meta-analysis was conducted and reported according to the proposal for conducting and reporting Meta-analysis of Observational studies and was registered with the International Prospective Register for Systematic Reviews. We performed a computerized systematic search through MEDLINE, EMBASE, and COCHRANE databases using the following search terms separately and in combination; "CTO," "Chronic total occlusion," "Chronic total coronary occlusion," "revascularization," "PCI," "Angioplasty," and "Recanalization." A similar search strategy was performed for abstracts of the major scientific sessions (American College of Cardiology, European Society of Cardiology, American Heart Associa-tion). We further screened the bibliographies of the retrieved studies, prior meta-analysis as well as ClinicalTrials.gov for any relevant studies not retrieved through the initial search. Our search was limited to the English language.

We incorporated in this meta-analysis studies that evaluated the effect of successful CTO PCI on LVEF. Studies had to include patients with a CTO who received successful PCI, and the LV function had to have been assessed before and after successful PCI.

| Data extraction and quality assessment
The informations were extracted by two autonomous investigators (MM, MS) including baseline study characteristics, patients' demographic and results of attention from the retrieved studies. Discrepancies among investigators were established by consensus.

\section{| Outcomes}

The main result of the present study was the mean dissimilarity in LVEF before and after successful CTO PCI. Secondary outcomes

included the mean difference in left ventricular enddiastolic volume (LVEDV) and Left ventricular endsystolic volume (LVESV) before and after successful PCI. To ensure homogeneity in the outcome definitions, The numerical values of the outcomes were tabulated. Outcomes were reported at the longest available followup.

\section{| Inclusion Criteria}

-Age (between 35 and 65 years).

-Known ischemic heart disease patients (by history, investigations or recurrent complaining of chest pain). -patients with totally occluded coronary artery.

\section{| Exclusion Criteria}

-Multi-Vessels diseased patient.

-Cardiomyopathic patients.

| All patients will be assessed as following -Medical history of subjects as history of : ischemic heart disease(anti-ischemic treatment, previous C.A or PCI). Diabetes Mellitus(on oral 
ISSN: 2536-9474 (Print)

ISSN: 2536-9482 (Online)
Fayoum University Medical Journal
Original article / FYMJ

El Khashab et al., 2019, 1 (2), 147-160 hypoglycemic drugs,HbA1c more than 6.5\%) Hypertension (on anti-hypertensive treatment ,SBP>140 and DBP > 90)

-Clinical examination ( signs of heart failure).

-Electrocardiography (ischemic changes includes

$\mathrm{T}$ wave, ST segment

, QRS complex).

-LV Echocardiography study to assess its function pre-totally occluded coronary revascularization by PCI and post the procedure within 1 month.

| Data synthesis and statistical analysis

Information were collected and coded to assist data handling and dual entered into Microsoft Access and data analysis was processed using Statistical Package of Social Science (SPSS) software version 18 in windows 7 .

Simple explanatory analysis in the form of numbers and percentages for qualitative statistics, and mathematics means as central tendency measurement, standard deviations as measure of dispersion for quantitative parametric information.

Quantitative data built-in in the study was first experienced for normality by One-Sample Kolmogorov-Smirnov test in each study group then inferential statistic tests were chosen.

For quantitative parametric information:

-In-depended student t-Test used to contrast measures of two independent groups of quantitative data.

For qualitative data :
L.V. function assessed by Two-dimensional (2D) echocardiography, M- mode echocardiography , Segmental wall motion index, Tissue Doppler \& Eyeball assessment are all used to assess the function of $\mathrm{LV}$, both during systole as well as in diastole. All techniques of echocardiography used to measure LV systolic function either quantitatively or qualitatively. All validation studies in LV systolic function assessment was done using transthoracic echocardiography(TTE)

-Chi square test to match teo of quite two qualitative groups. Bivariate Pearson correlation test to check between variables

-The P-value $\leq 0.05$ was considered the cut-off value for impact.

\section{RESULTS}

\section{| Demographic Data}

-This study was conducted on 100 patients in the outpatient cardiovascular clinic at Fayoum University Hospital after approval of local institution ethical committee.

-Patient age was between 39 and 65 year old with mean \pm SD equals $55.5 \pm 4.99$ years.

Gender distribution was as the following: 87 $(87 \%)$ were males and $13(13 \%)$ were females.

(Figure 1)

\section{| Risk Factors}

Table ( 1 ) below shows associated risk factors in studied patients. Smokers were $80 \%$ of cases. 
ISSN: 2536-9474 (Print)

ISSN: 2536-9482 (Online)
Original article / FYMJ

El Khashab et al., 2019, 1 (2), 147-160
| The most affected CTO vessels

LAD was the most frequently occluded vessel with $67 \%$, RCA and LCX were occluded totally in $22 \%$ and $11 \%$ of patients respectively.(Figure 2)

\section{| Mitral Valve}

Number of patients with Mitral Valve regurgitation pre and post intervention:

(Mitral Regurgitation severity increased without clinical evidence may be due to inter-operator variability) (Figure 3).

| Relation between ECHO parameters pre and post PCI

E Wave m/s, A Wave m/s, LVIDD mm, EF MMode EF Eye-ball and LVIDS $\mathrm{mm}$ were measured pre and pot PCI. Paired t test was applied to detect the effect of intervention on these parameters.

The only affected parameter was EF (M-Mode or Eye-ball) with statistically significant improvement after intervention (p: <0.001). below shows this effect. (Table 2)

\section{| L.V. Function Improvement}

L.V. Function Improvement was observed in $76 \%$ of patients. With no change in $14 \%$ and worsening in $10 \%$ of studied patints.(Figure 4)
Relation between L.V. Function Improvement and Sex, Smoking, D.M., HTN and IHD was tested by Pearson Chi-squared test. No statistical significant effect was found.

The only risk factor which had an effect on L.V function post intervention was the totally occluded coronary. 54(80\%) of LAD patients were improved. With 15(68.2\%) and 7(63\%) patients in RCA and LCX were improved respectively.

(Table 3).

\section{DISCUSSION}

The present study was to evaluate the effect of elective PCI to a CTO artery on LV functions, using conventional echocardiography.

In this study, 100 patients with a CTO artery selected and global LV systolic and diastolic functions examined by echo and TDI, before PCI and within one month after PCI.

Our findings suggest a survival benefit of successful CTO PCI Procedural success was associated with an improvement in left ventricular systolic function. The current study indicated that PCI provides functional and clinical profit in patients with CTO lesions. A sequences of small to medium-sized heterogenous observational studies have been performed that report the effect of CTO

recanalization on LVEF.Taken together, the results powerfully propose a modest $(<5 \%)$ 
ISSN: 2536-9474 (Print)

ISSN: 2536-9482 (Online)
Fayoum University Medical Journal
Original article / FYMJ

El Khashab et al., 2019, 1 (2), 147-160 improvement of regional and global LV function

when patients are selected on the presence of dysfunctional hibernating myocardium. The

greatest recovery in LV function is thus seen in

those patients with no prior history of MI, who

have regional dysfunction at baseline and a patent artery at follow up. [4]

Further studies have attempted to more precisely predict functional myocardial recovery using contrast enhanced MRI, dobutamine stress ECHO, wall thickness or a combination of these different modalities. Infarction of $<25 \%$ of the myocardial wall thickness strongly predicts recovery, $>75 \%$ predicts no recovery, and between these values lies a grey zone.[4]

However, a more recent study during the DES-era found no difference in in-hospital mortality between successful and unsuccessful cases. A number of potential mechanisms by which revascularisation of CTOs might improve prognosis have been proposed. These include prevention of adverse left ventricular remodelling, prevention of sudden cardiac death through improved electrical stability, and greater tolerance of any subsequent ACS events.[5] A growing body of studies have shown that the mechanisms by which PCI of a CTO artery might improve outcomes include reduction in adverse LV remodeling with preservation of LV function, increased electrical stability, and provision of collateral vessels for protection against future events, patients with reversible and fixed perfusion defects might benefit more from PCI procedure due to the improvements in myocardial blood flow and in the contractility within the affected myocardium.

CTO patients without significant myocardial perfusion defects usually have a short anatomic coronary lesion, abundant collaterals, and less angina pectoris presentation.[6]

| That comes in agreement with previous study performed by:

Misato Chimura, Shinichiro Yamada, et al, studied a total of 70 CTO lesions (in 70 patients) were tar- geted, and 60 lesions were effectively revascularized with PCI, and 10 lesions were unsuccessful Echocardiographic measurement showed a considerable recovery 9 months after successful PCI group ), whereas that did not alter significantly after failed PCI group.[7]

P. Wang, Y. Liu, et al, all the 43 patients were appropriate for analysis . 
ISSN: 2536-9474 (Print)

ISSN: 2536-9482 (Online)
Fayoum University Medical Journal
Original article / FYMJ

El Khashab et al., 2019, 1 (2), 147-160

Improvement of LVEF by CTO-PCI were

observed at up to 3 and 6 months.[8]

Mohamed Mahmoud, Mahmoud Ahmed A.

Elbaset et al, studied 30 patient with LAD CTO left ventricular function pre and post PCI and showed Enhancement in LVEF in $18(60 \%)$ of patients, unaffected in $4(13.3 \%)$ of patients, and decreased (but still normal function) in $8(26.6 \%)$ of patients.[9]

Michael Megaly MD, Marwan Saad MD, et al , thier meta-analysis of 34 studies with 2804 patients demon- strates that successful CTO PCI is associated with statistically significant increase in mean LVEF by $3.8 \%$ during a mean follow-up duration of 7.9 months.[10]

Wessam H. El Shafey, Said S. Montaser,et al, studied a total of 37 CTO lesions (in 40 patients) were targeted, Echocardiographic measurement showed a significant improvement 3 months after successful PCI group especially in patients with no past history of myocardial infarction.[11]

Yohei Sotomi , Atsunori Okamura, et al, studied a total of 37 CTO lesions (in 46 patients) were targeted, This study demonstrated that CTO-PCI improved regional longitudinal strain in donor area at 3 months follow-up without changes of LV ejection fraction.[12]

| While this disagree with :

-TOSCA (Total Occlusion Study of Canada) sub study which reported no improvement in LV function at one year.[13]

-Occluded Artery Trial(OAT), has shown no clinical benefit at 2year follow-up of revascularization when compared with medical therapy in asymptomatic or poorly symptomatic patients with subacute MI. however, most OAT patients had single- vessel disease and 93\% underwent single-vessel PCI, there are no data from randomized studies assessing effect of CTO revascularization on survival in patients with multivessel disease.[14]

-Banerjee et al. in another study reported that late PCI on persistent total LAD artery occlusion did not reduce rate of death, re-infarction, HF and no change was observed in LVEF compared with optimal medical therapy.[15] 
Tanaka et al. studied 27 patients and showed improvement in LV early diastolic filling after PCI [16] Carluccio et al. also had reported by Improvement of LV diastolic function.[1

\section{CONCLUSION}

PCI for a CTO has a beneficial effect on LV functions, myocardial contractility . So we recommend that :-

-PCI for a CTO has a beneficial effect on LV functions, improvement in regional and global LV functions and myocardial contractility after revascularization that can be predicted by Echocardiography.

-Further studies are recommended to assess viability of myocardium supplied by CTO before PCI.

\section{REFERENCES}

1. Shahbudin H. Rahimtoola, Vasken Dilsizian, et al , 2008 Chronic Ischemic Left Ventricular Dysfunction, JACC Cardiovasc Imaging. 2008 Jul 7; 1(4): 536-555.

2. Left ventricular global systolic function assessment by echocardiography, Ann Card Anaesth. 2016 Oct; 19(Suppl 1): S26-S34.

3. Roxy Senior, Avijit Lahiri, et al, Effect of revascularization on left ventricular remodeling in patients with heart failure from severe chronic ischemic left ventricular dysfunction 2001 American journal of cardiology.

4. Safley DM, Koshy S, et al. Changes in myocardial ischemic burden following percutaneous coronary intervention of chronic total occlusions. Catheter Cardiovasc Interv, 2011; 78(3): 337-43.

5. Jones DA, Weerackody R, et al. Successful recanalization of chronic total occlusions is associated with improved long- term survival. JACC Cardiovasc Interv, 2012; 5(4): 380-8.

6. Monteiro P, Antunes A,et al. Long- term clinical impact of 
coronary-collateral vessels after acute myocardial infarction. Rev Port Cardiol, 2003; 22: 10511061. 
7. Chimura M, Yamada S, et al (2019) Improvement of left ventricular function assessment by global longitudinal strain after successful percutaneous coronary intervention for chronic total occlusion. PLoS ONE 14(6): e0217092.

8. P. Wang, Y. Liu, et al. Evaluation of left ventricular function after percutaneous recanalization of chronic coronary occlusions Herz 2019 • 44:170-174.

9. Mohamed Mahmoud, Mahmoud Ahmed A. Elbaset, et al. assessment of changes in left ventricular functions after percutaneous coronary intervention of chronic total occlusion of left anterior descending artery; echocardiography and tissue doppler study ejpmr, 2017,4(05), 162172.

10. michael megaly md,marwan saad md,et al. meta-analysis of the impact of successful chronic total occlusion percutaneous coronary intervention on left ventricular systolic function and reverse remodeling j interv cardiol. 2018;31:562-571.

11. Wessam H. El Shafey, Said S. Montaser, et al. Assessment of left ventricular function before and after a percutanous coronary intervention to chronic total coronary occlusion:Doppler tissue imaging study Menoufia Medical Journal 2015, 28:400-405.

12. Yohei Sotomi, Atsunori Okamura, et al. Impact of revascularization of coronary chronic total occlusion on left ventricular function and electrical stability: analysis by speckle tracking echocardiography and signal-averaged electrocardiogram Int J Cardiovasc Imaging (2017) 33:815-823.

13. Dzavik V, Buller CE, Lamas GA, et al. Randomized trial of percutaneous coronary intervention for subacute infarct-related coronary artery occlusion to achieve long term patency and improve ventricular function: the Total Occlusion Study of Canada (TOSCA)-2trial. Circulation, 2006; 114: 2449-57.

14. Hochman JS, Lamas GA, Buller CE, Dzavik V, et al, Occluded Artery Trial Investigators. Occluded Artery Trial Investigators. Coronary Intervention for Persistent Occlusion after 
Myocardial Infarction. N Engl J Med; 2006; 355: 2395-2407.

15. Tanaka H, Kawai H, Tatsumi K, Kataoka T, Onishi T, Nose T, Mizoguchi T, Yokoyama M.Improved regional myocardial diastolic function assessed by strain rate imaging in patients with coronary artery disease undergoing percutaneous coronary intervention. J Am Soc Echocardiogr, 2006; 19(6): 756-62.

16. Pantano P, Vincenti G, Giombolini C, Ragni T, Reboldi G, Gentile F, Ambrosio G.Effect of revascularizing viable myocardium on left ventricular diastolic function in patients with ischaemic cardiomyopathy. Eur Heart J, 2009; 30(12): 1501-9 
ISSN: 2536-9474 (Print)

ISSN: 2536-9482 (Online)

\section{Figures and Tables}

(Figure 1)

demographic characters in study groups (sex)

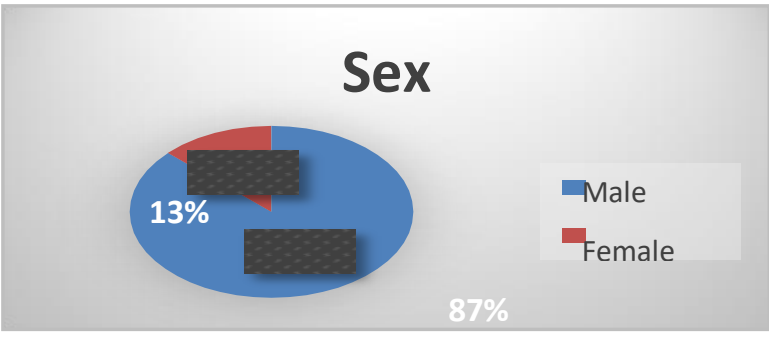

(Figure 2)

The affected CTO vessels in study patients

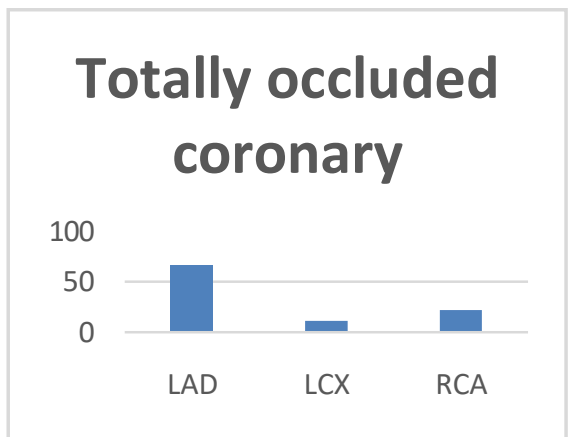

(Figure 3)

Effect of PCI to CTO vessels on Mitral Valve regurgitation

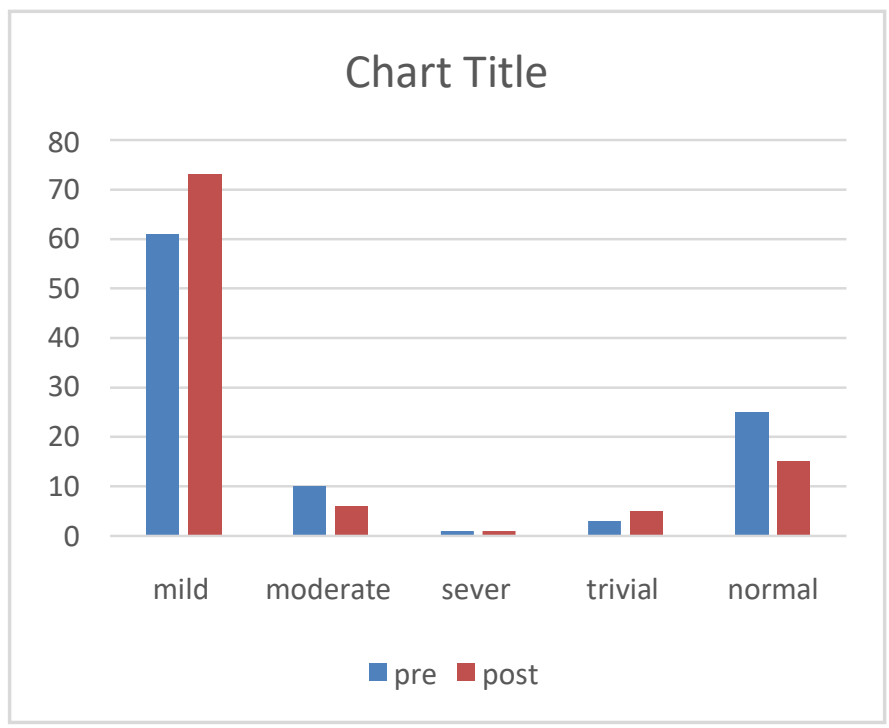




\section{(figure 4)}

Comparison between L.V. function improvement before \& after CTO PCI

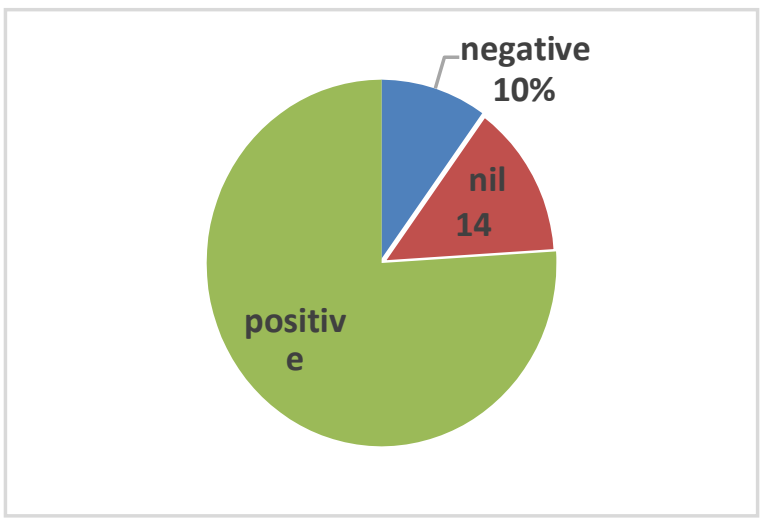

Table (1) below shows associated risk factors in studied patients. Smokers were $80 \%$ of cases.

\begin{tabular}{|c|c|c|c|}
\hline \multirow{3}{*}{ Smoking } & & Count & $\%$ \\
\hline & No & 20 & $20.0 \%$ \\
\hline & Yes & 80 & $80.0 \%$ \\
\hline \multirow[t]{2}{*}{ D.M. } & No & 51 & $51.0 \%$ \\
\hline & Yes & 49 & $49.0 \%$ \\
\hline \multirow[t]{2}{*}{ HTN } & No & 46 & $46.0 \%$ \\
\hline & Yes & 54 & $54.0 \%$ \\
\hline \multirow[t]{2}{*}{ Past history of IHD } & No & 96 & $96.0 \%$ \\
\hline & Yes & 4 & $4.0 \%$ \\
\hline \multirow[t]{2}{*}{ OCP } & No & 100 & $100.0 \%$ \\
\hline & Yes & 0 & $0.0 \%$ \\
\hline \multirow[t]{2}{*}{ Drug Addict } & No & 100 & $100.0 \%$ \\
\hline & Yes & 0 & $0.0 \%$ \\
\hline
\end{tabular}


Table (2) below shows Changes in echocardiographic data pre-\&post- CTO PCI

\begin{tabular}{|c|c|c|c|c|c|}
\hline & & Mean & $\begin{array}{c}\text { Std. } \\
\text { Deviation }\end{array}$ & $t$ & $\begin{array}{c}\mathrm{p}- \\
\text { value }\end{array}$ \\
\hline \multirow{2}{*}{$\begin{array}{c}\text { E Wave } \\
\mathrm{m} / \mathrm{s}\end{array}$} & Pre & 0.5436 & 0.16335 & \multirow{2}{*}{$1 . \overline{085-}$} & \multirow{2}{*}{0.281} \\
\hline & Post & 1.1458 & 5.54351 & & \\
\hline \multirow{2}{*}{$\begin{array}{c}\text { A } \\
\text { Wave } \\
\mathrm{m} / \mathrm{s}\end{array}$} & Pre & 0.63922 & 0.179219 & \multirow[b]{2}{*}{$-.966-$} & \multirow[b]{2}{*}{0.336} \\
\hline & Post & 1.0199 & 3.94039 & & \\
\hline \multirow{2}{*}{$\begin{array}{c}\text { LVIDD } \\
\mathrm{mm}\end{array}$} & Pre & 54.24 & 5.652 & \multirow{2}{*}{$1.558-$} & \multirow{2}{*}{0.122} \\
\hline & Post & 54.97 & 5.385 & & \\
\hline \multirow{2}{*}{$\begin{array}{c}\text { LVIDS } \\
\mathrm{mm}\end{array}$} & Pre & 40.64 & 5.210 & \multirow{2}{*}{1.866} & \multirow{2}{*}{0.065} \\
\hline & Post & 39.75 & 6.781 & & \\
\hline \multirow{2}{*}{$\begin{array}{l}\text { EF M- } \\
\text { Mode }\end{array}$} & Pre & $50.0600 \%$ & $8.03756 \%$ & \multirow{2}{*}{$\begin{array}{c}- \\
7.140-\end{array}$} & \multirow{2}{*}{$<0.001$} \\
\hline & Post & $54.1500 \%$ & $9.25222 \%$ & & \\
\hline \multirow{2}{*}{$\begin{array}{l}\text { EF } \\
\text { Eye- } \\
\text { ball }\end{array}$} & Pre & $50.1000 \%$ & $8.03967 \%$ & \multirow{2}{*}{ 7.957- } & \multirow[b]{2}{*}{$<0.001$} \\
\hline & Post & $54.4900 \%$ & $8.44769 \%$ & & \\
\hline
\end{tabular}

Table(3) Relations between L.V. Function Improvement \& different risk factors

\begin{tabular}{|c|c|c|c|c|c|c|c|c|}
\hline & \multicolumn{6}{|c|}{ L.V. Function Improvement } & \multirow{3}{*}{$\begin{array}{c}\text { p- } \\
\text { value }\end{array}$} \\
\hline & & \multicolumn{2}{|c|}{ negative } & \multicolumn{2}{|c|}{ nil } & \multicolumn{2}{|c|}{ positive } & \\
\hline & & $\mathrm{N}$ & $\%$ & $\mathrm{~N}$ & $\%$ & $\mathrm{~N}$ & $\%$ & \\
\hline \multirow{3}{*}{ Sex } & Male & 1 & 11.5 & 1 & 11.5 & 6 & 77.0 & \multirow{3}{*}{$\begin{array}{c}0.101 \\
\mathrm{a}\end{array}$} \\
\hline & & 0 & $\%$ & 0 & $\%$ & 7 & $\%$ & \\
\hline & $\begin{array}{c}\text { Femal } \\
\mathrm{e}\end{array}$ & 0 & $0.0 \%$ & 4 & $\begin{array}{l}30.8 \\
\%\end{array}$ & 9 & $\begin{array}{l}69.2 \\
\%\end{array}$ & \\
\hline \multirow{2}{*}{$\begin{array}{l}\text { Smokin } \\
\text { g }\end{array}$} & No & 4 & $\begin{array}{l}20.0 \\
\%\end{array}$ & 4 & $\begin{array}{c}20.0 \\
\%\end{array}$ & $\begin{array}{l}1 \\
2\end{array}$ & $\begin{array}{l}60.0 \\
\%\end{array}$ & \multirow{2}{*}{$\begin{array}{c}0.136 \\
\mathrm{a}\end{array}$} \\
\hline & Yes & 6 & $7.5 \%$ & 1 & 12.5 & 6 & 80.0 & \\
\hline \multirow{2}{*}{ D.M. } & No & 7 & $\begin{array}{l}13.7 \\
\%\end{array}$ & 6 & $\begin{array}{l}11.8 \\
\%\end{array}$ & $\begin{array}{l}3 \\
8\end{array}$ & $\begin{array}{l}74.5 \\
\%\end{array}$ & \multirow{2}{*}{0.397} \\
\hline & Yes & 3 & $6.1 \%$ & 8 & 16.3 & $\begin{array}{l}3 \\
8\end{array}$ & $\begin{array}{l}77.6 \\
\%\end{array}$ & \\
\hline \multirow{2}{*}{ HTN } & No & 7 & $\begin{array}{l}15.2 \\
\%\end{array}$ & 6 & $\begin{array}{c}13.0 \\
\%\end{array}$ & $\begin{array}{l}3 \\
3\end{array}$ & $\begin{array}{l}71.7 \\
\%\end{array}$ & \multirow{2}{*}{0.276} \\
\hline & Yes & 3 & $5.6 \%$ & 8 & $\begin{array}{c}14.8 \\
\%\end{array}$ & $\begin{array}{l}4 \\
3\end{array}$ & $\begin{array}{l}79.6 \\
\%\end{array}$ & \\
\hline \multirow{2}{*}{$\begin{array}{c}\text { Past } \\
\text { history } \\
\text { of IHD }\end{array}$} & No & 9 & $9.4 \%$ & $\begin{array}{l}1 \\
4\end{array}$ & $\begin{array}{l}14.6 \\
\%\end{array}$ & $\begin{array}{l}7 \\
3\end{array}$ & $\begin{array}{l}76.0 \\
\%\end{array}$ & \multirow{2}{*}{0.467} \\
\hline & Yes & 1 & $\begin{array}{l}25.0 \\
\%\end{array}$ & 0 & $0.0 \%$ & 3 & $\begin{array}{c}75.0 \\
\%\end{array}$ & \\
\hline $\begin{array}{l}\text { Totally } \\
\text { occluded }\end{array}$ & LAD & $\begin{array}{l}1 \\
0\end{array}$ & $\begin{array}{l}14.9 \\
\%\end{array}$ & 3 & $4.5 \%$ & $\begin{array}{l}5 \\
4\end{array}$ & $\begin{array}{l}80.6 \\
\%\end{array}$ & 0.001 \\
\hline
\end{tabular}

